

\title{
A porphyrin-based microporous network polymer that acts as an efficient MARK catalyst for cyclooctene and cyclohexane oxidation under mild conditions
}

\author{
Ariana R. Antonangelo ${ }^{\mathrm{a}}$, C. Grazia Bezzu ${ }^{\mathrm{b}}$, Sabeeha S. Mughal ${ }^{\mathrm{c}}$, Talita Malewschik ${ }^{\mathrm{a}}$, Neil B. \\ McKeown $^{\mathrm{b}}$, Shirley Nakagaki ${ }^{\mathrm{a}}$,
}

a Departamento de Química, Universidade Federal do Paraná (UFPR), Curitiba 81531-990, Brazil
b EastChem School of Chemistry, The University of Edinburgh, Edinburgh, Scotland EH9 3FJ, UK
c School of Chemistry, Cardiff University, Cardiff, Wales CF10 3AT, UK

\section{A R T I C L E I N F O}

\section{Keywords:}

Porphyrins

Polymers of Intrinsic Microporosity (PIMs)

Porous

Heterogeneous catalysis

Oxidation

\begin{abstract}
A B S T R A C T
The highly efficient dibenzodioxin-forming reaction between the (pentafluorophenyl)porphyrin manganese(III) (MnP) and hexahydroxytriptycene $(\mathrm{HHT})$ provide a new microporous network polymer ( $\mathrm{P} 1)$, which demon-strated a large surface area $\left(1080 \mathrm{~m}^{2} \mathrm{~g}^{-1}\right)$ and proved to be an efficient solid for heterogeneous catalysis for cyclooctene and cyclohexane oxidation under mild conditions and with high capacity of recovery and reuse in many catalytic cycles.
\end{abstract}

\section{Introduction}

Oxidation reactions of organic compounds, especially alkenes and alkanes, play an important role in the chemical industry, both in or-ganic synthesis and in the production of bulk and fine chemicals. The development of efficient and selective methods that employ mild con-ditions and avoid toxic metal reagents is the major challenge in this area [1]. In this regard, significant progress has been achieved within the area of homogeneous molecular catalysis, especially using por-phyrins. Synthetic metalloporphyrins, particularly those containing iron and manganese cations, have been widely studied as catalysts in many oxidation processes and as models for cytochrome P450 enzymes [2-6].

The synthetic development of novel catalysts is based upon a growing understanding of the mechanism of action and has led to im-prove catalytic results in homogeneous catalysis using porphyrins [4-6]. Despite the efforts in the synthesis of more robust porphyrins, the catalytic process employing such compounds in homogeneous medium still have some drawbacks, such as difficulty or impossibility of the catalyst recovery, formation of $\mu$-oxo dimmers or oxidative de-gradation of the porphyrin ring (even in a small extent) and con-tamination of the products formed at the end of the reaction [2-6]. In this regard, the search for more stable, efficient and selective catalysts, combined with the desire for recovery and reuse has also led to a growing interest in using porphyrin-based materials for heterogeneous catalysis [7-14]. Hence, metalloporphyrins have been immobilized on many different supports [7-9], and also incorporated within porous materials, such as Metal Organic Frameworks (MOFs) $[9,10]$ and porous network polymers [11-14]. These materials function as solid catalyst for heterogeneous process since the presence of porous en-hances access of the substrate to the active metal catalytic centers of the solid catalyst. Moreover, the high density of active sites in these ma-terials enhances catalytic performance. Although a number of research groups have explored the use of metalloporphyrins as building blocks for the design of porous polymers, catalytic studies using these mate-rials are still rare [9-14].

Polymers of Intrinsic Microporosity (PIMs) are highly rigid amor-phous materials, easily prepared using dibenzodioxin forming reac-tions, for which microporosity is generated from their rigid and con-torted structures [15]. Insoluble networks PIMs with high surface area (up to $1000 \mathrm{~m}^{2} \mathrm{~g}^{-1}$ ) and potential use in heterogeneous catalysis have been prepared previously using planar functional units such as phtha-locyanines and porphyrins $[12,13,16]$. These materials are assembled via covalent bond rather than by formation of usually weaker co-ordination or hydrogen bonds and display high chemical and thermal stability which encourage the synthesis of new network PIMs and their assessment for heterogeneous oxidation catalysis.

For the present study, the dibenzodioxin-forming reaction [16] be-tween (pentafluorophenyl)porphyrin manganese(III) (MnP) and 9,10-diethyl2,3,6,7,12,13-hexahydroxytriptycene (HHT) was used to pre-pare a new network PIM porphyrin-based (P1) (Scheme 1). The new polymer exhibits remarkable activity and stability on catalytic

\footnotetext{
Corresponding author.

E-mail address: shirleyn@ufpr.br (S. Nakagaki).
} 

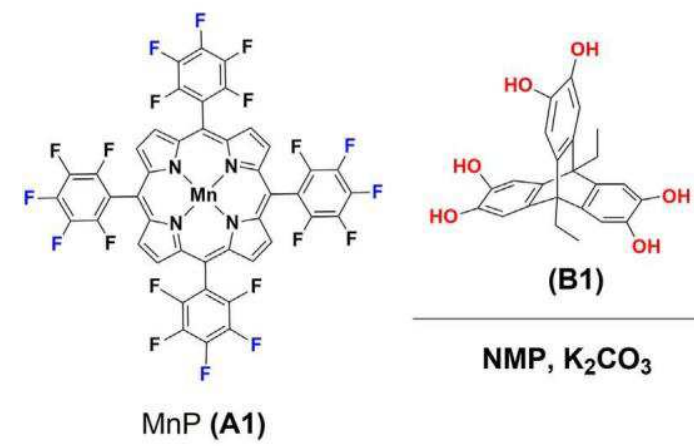

porphyrin-based microporous

Scheme 1. Schematic representation of $\mathrm{P} 1$ preparation. network polymer

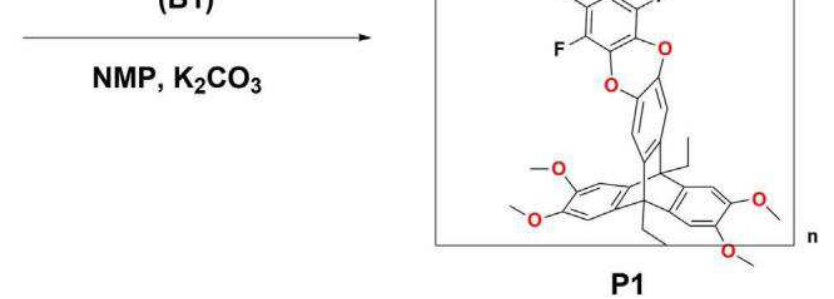

oxidation of cyclooctene and cyclohexane under heterogeneous condi-tions with high capacity of recovery.

\section{Experimental}

\subsection{General information}

The free-base porphyrin $\left(\mathrm{H}_{2} \mathrm{P}\right)$ [17], the metalloporphyrin $(\mathrm{MnP})$ [18], the compounds 9,10-diethyl-2,3,6,7,12,13-hexahydroxy-triptycene (HHT) [19] and the 2,3-dihydroxy-9,10-dimethyltriptycene (DHT) [20] were synthesized as reported previously (see Supporting Information SI). Iodosylbezene ( $\mathrm{PhIO})$ was prepared according to a literature procedure [21], assayed by iodometric titrations and stored in a freezer.

\subsection{Synthesis and characterization of the network PIM porphyrin P1}

The polymer $\mathrm{P} 1$ was prepared by reacting the metalloporphyrin $\mathrm{MnP}$ (monomer A1) and 9,10-diethyl-2,3,6,7,12,13-hexahydroxy-triptycene HHT (monomer B1) (Scheme 1) according to the reported procedure [16]. The metalloporphyrin $\mathrm{MnP}(0.17 \mathrm{~g}, 0.156 \mathrm{mmol}), 9,10$-diethyl-2,3,6,7,12,13hexahydroxytriptycene $\mathrm{HHT}(0.1 \mathrm{~g}, 0.208 \mathrm{mmol})$ and anhydrous $\mathrm{K}_{2} \mathrm{CO}_{3}$ $(0.32 \mathrm{~g}, 2.34 \mathrm{mmol})$ were stirred in anhydrous NMP $(5 \mathrm{~mL})$ at $170{ }^{\circ} \mathrm{C}$ under nitrogen atmosphere. After about $24 \mathrm{~h}$ the system was allowed to reach room temperature, me-thanol $(30 \mathrm{~mL})$ was added and the mixture was stirred for 30 min, from which a black solid (P1) was filtered off. The solid was purified by Soxhlet extraction and reflux in various solvents (in the order THF, $\mathrm{CHCl}_{3}$, $\mathrm{CHCl}_{2}$, acetone and methanol). The solid was dried in vacuum oven for $6 \mathrm{~h}$ at $110{ }^{\circ} \mathrm{C}$ (yield 90\%). Elemental analysis (\%) for $\mathrm{C}_{78} \mathrm{H}_{32} \mathrm{O}_{10} \mathrm{~F}_{12} \mathrm{~N}_{4} \mathrm{Mn}$ : calcd C 63.82, H 2.20, N 3.82; found: C 55.40, H 1.80, N 4.20 ICP OES (Mn, \%) calcd.: 3.74, found: 3.24 . BET surface area $=1080 \mathrm{~m}^{2} \mathrm{~g}^{-1}$. IR $\left(\mathrm{cm}^{-1}\right): 1651,1455,1419,1334,1300,1254,1157,1064,1006,947,797$, 759, 705. UV-vis $\lambda_{\max }$ (mineral oil, nm): 475, 376. TGA (nitrogen): $3.5 \%$ loss of mass $<200{ }^{\circ} \mathrm{C}$. Initial weight loss due to thermal degradation commences at $\sim 400{ }^{\circ} \mathrm{C}$ (Fig. S17, SI). Note that the mass loss $<200{ }^{\circ} \mathrm{C}$ is ascribed to the removal of ad-sorbed gas $\left(\mathrm{O}_{2}, \mathrm{~N}_{2}, \mathrm{CO}_{2}\right)$ and solvent or water molecules, which we account for the lower than expected carbon content from elemental analysis. Moreover, thermal degradation results in a loss of mass of only

$\sim 50 \%$ of original weight up to $1000{ }^{\circ} \mathrm{C}$, indicating that carbonization is occurring, which is consistent with the low values for carbon obtained during elemental analysis.

\subsection{Catalytic reactions}

The efficiency of the network PIM porphyrin (P1) as catalyst for oxidation reactions was tested using (Z)-cyclooctene (previously pur-ified on neutral alumina column) and cyclohexane as substrates using iodosylbenzene as oxygen donor. The reactions were performed in a $1.5 \mathrm{~mL}$ glass flask equipped with a magnetic stirrer, in a dark chamber. The solvent mixture (acetonitrile/dichloromethane,ACN:DCM 1:1, v/v) and the substrates were purged with argon for $15 \mathrm{~min}$. The catalyst P1 $(0.001 \mathrm{~g}, 0.00059 \mathrm{mmol})$ and the oxidant iodosylbenzene $(0.0013 \mathrm{~g}, 0.0059 \mathrm{mmol})(\mathrm{P} 1 / \mathrm{PhIO}$ at a molar ratio of 1:10) were added in the reaction flask and they were also purged with argon for $15 \mathrm{~min}$. Then, the mixture of solvents (ACN:DCM, 1:1) was added to the reactions flasks, followed by addition of the substrates ( $\mathrm{P} 1 / \mathrm{PhIO} /$ substrate molar ratio of 1:10:1000). The molar ratio was based on the amount of metal of the polymer P1 measures by ICP (heterogeneous catalysis) or based on the molecular mass of the metalloporphyrin $\mathrm{MnP}$ (homogeneous catalysis). The oxidation reactions were performed under magnetic stirring, for $1 \mathrm{~h}$, at room temperature, in the absence of light. At the end of the reaction, the excess of iodosylbenzene was eliminated by adding a solution of sodium sulfite in acetonitrile. The catalyst P1 remained insoluble during the reaction, so the process was heterogeneous in all cases. At the end of the heterogeneous reaction, the reaction mixture was separated from the insoluble catalysts by centrifugation and the supernatant was transferred to a volumetric flask $(2 \mathrm{~mL})$. The solid catalyst was washed three times with the mixture of solvents (ACN:DCM) to extract any reaction products that might have adsorbed onto the solids catalysts. The washing solutions were added to the previously separated reaction supernatant in a volumetric flask $(2 \mathrm{~mL})$. In case of the homogeneous catalysis $(\mathrm{MnP})$, the reaction mixture was transferred directly to a volumetric flask $(2 \mathrm{~mL})$ by the end of the re-action.

To study the recyclability of $\mathrm{P} 1$, the solid catalyst was recovered after each use by centrifugation, washed with different solvents (water, acetonitrile, dichloromethane and methanol) and dried at $100{ }^{\circ} \mathrm{C}$ on a vacuum oven for about $12 \mathrm{~h}$. The dried solid was then reused in a new catalytic reaction in the same conditions as the ones described above.

The products were analyzed by gas chromatography using bromo-benzene as internal standard. Product yields were based on the quantity of PhIO added to each reaction. 
(a)

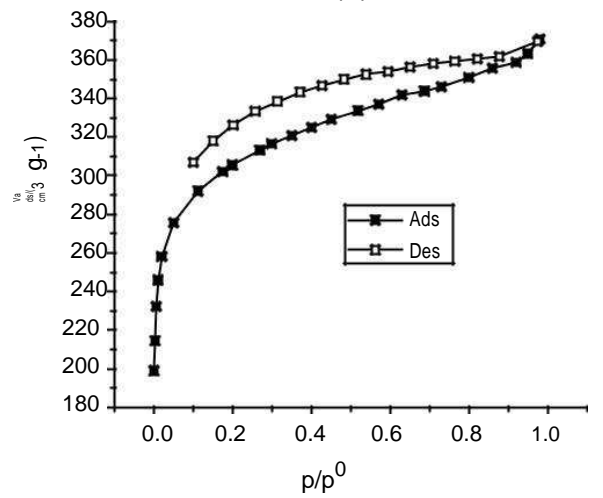

(b)

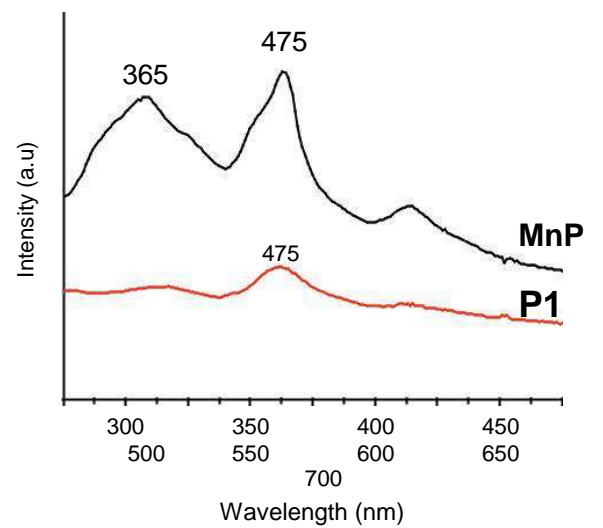

Fig. 1. (a) Nitrogen adsorption/desorption isotherm for P1 (BET surface area $=1080 \mathrm{~m}^{2} \mathrm{~g}^{-1}$ ), (b) UV-vis spectra of the MnP (monomer A1) and network PIM porphyrin P1 (both samples in mineral oil).

\section{Results and discussion}

\subsection{Synthesis and characterization of the network PIM porphyrin P1}

Significant nitrogen $\left(\mathrm{N}_{2}\right)$ adsorption at $77 \mathrm{~K}$ for $\mathrm{P} 1$ at low values of relative pressure $\left(\mathrm{P} / \mathrm{P}^{0}\right)$ and the isotherm shape (Type I) [22] are both consistent with a predominantly microporous structure (Fig. 1a). The isotherm permitted an apparent BET surface area of $1080 \mathrm{~m}^{2} \mathrm{~g}^{-1}$ to be calculated. The hysteresis observed for $\mathrm{P} 1$ extends down to low relative pressures and this characteristic may be attributed to swelling of the polymer rather than to the presence of mesopores $[12,15,23]$.

The UV-vis spectrum in mineral oil (Fig. 1b) of the metallopor-phyrin $\mathrm{MnP}$ showed the Soret band at $475 \mathrm{~nm}$ and the charge transfer band at 365 $\mathrm{nm}$, both consistent with $\mathrm{Mn}$ (III) porphyrins [24]. The same bands were observed in the spectrum of the polymer P1 which suggest the presence of the $\mathrm{Mn}(\mathrm{III})$ porphyrin in its structure.

Thermogravimetric analysis (TGA) (SI, Fig. S17) indicated that the polymer $\mathrm{P} 1$ has excellent thermal stability with decomposition starting as high as $350{ }^{\circ} \mathrm{C}$, which can be important for some catalytic processes.

The synthesis of the polymer $\mathrm{P} 1$ involves an aromatic nucleophilic substitution $\left(\mathrm{S}_{\mathrm{N}} \mathrm{Ar}\right)$ mechanism. As reported previously, the fluorine atoms in the para position of the porphyrin core are readily substituted by nucleophiles $[25,26]$. This is followed by a second rapid in-tramolecular substitution on the neighboring fluorine atoms when ca-techols are used as nucleophiles [16]. Therefore, in order to confirm the reaction between the monomers MnP and HHT (Scheme 1), a model $\mathrm{S}_{\mathrm{N}} \mathrm{Ar}$ reaction using the free-base tetrakis(pentafluorophenyl)porphyrin $\left(\mathrm{H}_{2} \mathrm{P}\right)$ and four molar equivalents of the 2,3-dihydroxy-9,10-dimethyl-triptycene (DHT) was performed (Scheme 2), according to the reported procedure [16]. The novel triptycene-substituted porphyrin $\left(\mathrm{H}_{2}\right.$ Porph1) was characterized by MALDI-MS and ${ }^{1} \mathrm{H}$ and ${ }^{19} \mathrm{~F}$ NMR spectroscopy, all of which confirmed its structure (see S I).

\subsection{Catalytic reactions}

(Z)-cyclooctene is a useful diagnostic substrate as it is easily oxi-dized in the presence of metalloporphyrins as catalysts and (Z)-cy-cloocteneoxide is usually the sole product $[27,28]$. For comparison, the performance of MnP as catalyst was also determined (Table 1) as it had shown previously high catalytic activity in homogeneous oxidation reactions [27]. This enhanced performance of the porphyrin $\mathrm{MnP}$ can be attributed mainly to its greater stability under oxidation conditions, resulting from the electron withdrawing nature of the penta-fluorophenyl substituents.

The polymer $\mathrm{P} 1$ showed excellent activity for the oxidation of (Z)cyclooctene ( $80 \%$ yield) (Table 1), similar to the activity of the MnP in homogeneous medium (86\% yield) suggesting that the catalytic centers of $\mathrm{MnP}$ in the $\mathrm{P} 1$ structure are readily accessible to both cyclooctene and $\mathrm{PhIO}$ reactants. The control reaction using $\mathrm{PhIO}$ in the absence of any catalyst showed low epoxide yield (7\%), proving that catalytic activity is due to the presence of $\mathrm{MnP}$ or $\mathrm{P} 1$.

Cyclohexane is less reactive than cyclooctene and its oxidation can produce a mixture of cyclohexanone (K) and cyclohexanol (A) (so-called $\mathrm{K}$ A oil), which is of considerable importance in the industrial production of nylon [1].

The catalytic oxidation using metalloporphyrins usually affords both cyclohexanone (K) and cyclohexanol (A) (as major products [27,28]). Both $\mathrm{MnP}$ and $\mathrm{P} 1$ showed selectivity for the alcohol in the cyclohexane oxidation (Table 2), which is also in agreement with homogeneous catalysis using other metalloporphyrins [27-30]. The polymer P1 showed catalytic activity similar to that achieved with the $\mathrm{MnP}$ in homogeneous medium ( $\sim 50 \%$ yield) and a higher alcohol se-lectivity ( $98 \%$ for $\mathrm{P} 1$ and $83 \%$ for $\mathrm{MnP}$ ) as shown in Table 2. Although much effort has been made in the development of catalysts for oxida-tion of cyclohexane [27,29-31], few catalysts with efficient catalytic
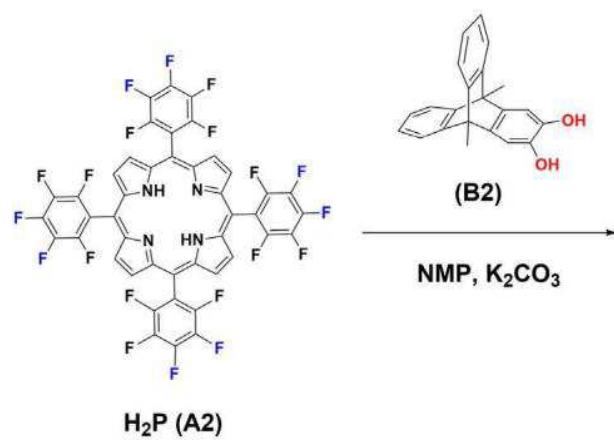

$\mathrm{H}_{2} \mathrm{P}$ (A2)

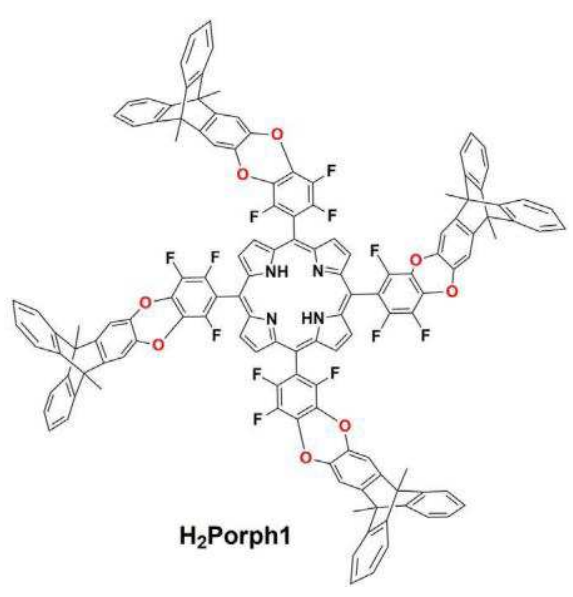

Scheme 2. Schematic representation of the $\mathrm{H}_{2} \mathrm{Porph} 1$ preparation. 
Table 1

Oxidation of (Z)-Cyclooctene using $\mathrm{PhIO}$ as oxidant and the porphyrin PIM network $\mathrm{P} 1$ as solid catalyst for heterogeneous process or the precursor $\mathrm{MnP}$ as homogeneous one.

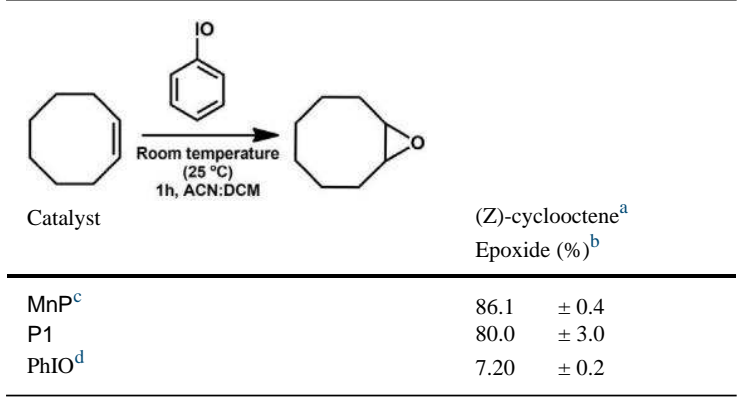

a Reactions conditions: reaction time $=1 \mathrm{~h}$, solvent mixture of acetonitrile/dichlorometane (ACN:DCM, 1:1 v/v), room temperature $\left(25{ }^{\circ} \mathrm{C}\right.$ ), Catalyst $(\mathrm{P} 1) / \mathrm{PhIO} /$ substrate molar ratio $=1: 10: 1000$.

$\mathrm{b}$ The product yields were calculated based on the amount of iodo-sylbenzene used in the reactions.

${ }^{\mathrm{c}}$ Homogeneous catalysis with the metalloporphyrin $\mathrm{MnP}$ (monomer A1).

${ }^{\mathrm{d}}$ Control reaction using only substrate $+\mathrm{PhIO}$

Table 2

Oxidation of cyclohexane using $\mathrm{PhIO}$ as oxidant and the porphyrin PIM network P1 as heterogeneous catalyst or the precursor porphyrin $\mathrm{MnP}$ as homogeneous catalysts.

\begin{tabular}{|c|c|c|c|}
\hline \multirow[t]{2}{*}{ Catalyst } & \multicolumn{3}{|l|}{ Cyclohexane $^{a}$} \\
\hline & $\operatorname{Alcohol}^{\mathrm{b}}(\%)$ & Ketone $^{\mathrm{b}}(\%)$ & Alcohol selectivity (\%) \\
\hline $\mathrm{MnP}^{\mathrm{c}}$ & $54.0 \pm 3.0$ & $10.7 \pm 0.5$ & 83.6 \\
\hline P1 & $53.1 \pm 1.3$ & $1.0 \pm 0.4$ & 98.2 \\
\hline $\mathrm{PhIO}^{\mathrm{d}}$ & Not detected & Not detected & - \\
\hline
\end{tabular}

a Solvent mixture of acetonitrile/dichlorometane (ACN:DCM, 1:1 v/v), room tem-perature $\left(25^{\circ} \mathrm{C}\right)$, Catalyst $(\mathrm{P} 1) / \mathrm{PhIO} /$ substrate molar ratio $=1: 10: 1000$

$\mathrm{b}$ The products yields were calculated based on the amount of iodosylbenzene used in the reactions.

${ }^{\mathrm{c}}$ Homogeneous catalysis with the metalloporphyrin $\mathrm{MnP}$ (monomer A1).

d Control reaction using only substrate and PhIO.

activity under mild conditions have been reported in heterogeneous catalysis [9-11,28,32]. Furthermore, in some cases the catalyst showed selectivity for ketone rather than alcohol $[7,10,33]$. Nevertheless, few studies have shown recyclability tests using cyclohexane as substrate [10].

The catalytic activity and the alcohol selectivity of P1 for cyclo-hexane oxidation is impressive in comparison to some previously cat-alytic results using other materials in heterogeneous medium [8,27,29-31]. In general, for cyclohexane oxidation, metalloporphyrins show lower catalytic activity in heterogeneous medium than in solution (homogeneous catalysis) [27-30]. These impressive results suggest the stability of the active sites within the P1 structure and also the easy accessibility of the catalytic centers to the cyclohexane substrate in the polymer structure.

In general, microporous materials usually show better catalytic ac-tivity for substrates of smaller size [33-35]. The excellent catalytic activity of polymer P1 after only one hour of reaction and under mild conditions for both substrates investigated, suggests that they can readily access the catalytic sites inside the porous structure of the material. Further investigations using substrates of diff erent steric bulk are being planned.

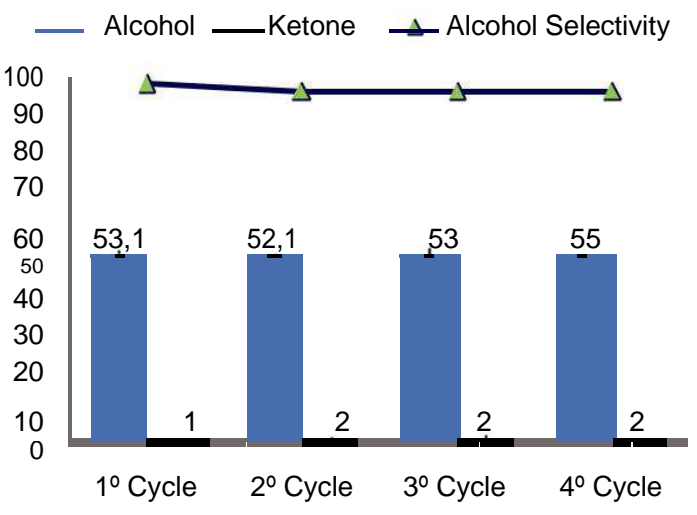

Fig. 2. Study of the recyclability of the catalyst solid P1 for cyclohexane oxidation re-action under the same conditions mentioned in the Table 2.

catalysis in relation to homogeneous one is the recyclability of the catalyst. Therefore, the polymer P1 was easily recovered from the re-action medium and reused without loss of the catalytic activity during at least four catalytic cycles (Fig. 2). Moreover, the catalyst P1 main-tained the high alcohol selectivity in all cycles studied.

We ascribe this remarkable retention of catalytic activity to the highly robust nature of the polymer and its rigidity, which maintains site-isolation of the metal centers and stops self-oxidation of the por-phyrin ligands.

In addition, heterogeneous catalysis using $\mathrm{P} 1$ provides greater purity of the products compared to homogeneous using $\mathrm{MnP}$ since they are separated by simple centrifugation and washing of the solid cata-lyst.

\section{Conclusions}

To conclude, a microporous network polymer P1 was easily pre-pared by an efficient dibenzodioxin-forming reaction from a simple manganese(III)porphyrin precursor (MnP) which has recognized cata-lytic activity in homogenous oxidation catalysis. The polymer $\mathrm{P} 1$ proved to be a highly active catalyst for (Z)-cyclooctene and cyclo-hexane oxidation, showing catalytic activity comparable to the MnP precursor in solution (homogeneous catalysis). In addition, the P1 polymer showed excellent catalytic activity in the oxidation of cyclo-hexane with high alcohol selectivity under mild conditions and was also easily recovered by centrifugation and reused without loss of catalytic activity, maintaining a high alcohol selectivity in all cycles studied.

We expected that this work will contribute scientifically to research on porous porphyrinic materials for heterogeneous catalysis under mild conditions, mainly for the oxidation of inert substrates like cyclo-hexane, and thus leads to the development of some industrially useful materials in the future.

\section{Acknowledgment}

The authors are grateful to CAPES (Coordenação de Aperfeiçoamento de Pessoal de Nível Superior), CNPq (Conselho Nacional de Desenvolvimento Científico e Tecnológico(Cnpq grant 202000/2014-1))- Science without Borders, Fundação Araucária, Universidade Federal do Paraná and The University of Edinburgh, for financial support. 


\section{References}

[1] J. Bäckvall, Modern Oxidation Methods, second ed., Wiley-VCH, Germany, 2010.

[2] J.T. Groves, T.E. Nemo, R.S. Myer, Hydroxylation and epoxidation catalyzed by ironporphine complexes. Oxygen transfer from iodosylbenzene, J. Am. Chem. Soc. 101 (1979) 1032-1033.

[3] D. Mansuy, A brief history of the contribution of metalloporphyrin models to cytochrome P450 chemistry and oxidation catalysis, C. R. Chimie. 10 (2007) 392-413.

[4] D. Dolphin, T.G. Traylor, L.Y. Xie, Polyhaloporphyrins: unusual ligands for metals and metal-catalyzed oxidations, Acc. Chem. Res. 30 (1997) 251-259.

[5] V.S. Da Silva, W.C.S. Vieira, A.M. Meireles, G.M. Ucoski, S. Nakagaki, Y.M. Idemori, G. DeFreitas Silva, Biomimetic oxidation of cyclic and linear alkanes: high alcohol selectivity promoted by a novel manganese porphyrin catalyst, New J. Chem. 41 (2017) 997-1006

[6] V.S. Da Silva, L.I. Teixeira, E. Nascimento, Y.M. Idemori, G. DeFreitas Silva, New manganese porphyrin as biomimetic catalyst of cyclohexane oxidation: eff ect of water or imidazole as additives, Appl. Catal. A Gen. 469 (2014) 124-131.

[7] G.S. Machado, G.G.C. Arízaga, F. Wypych, S. Nakagaki, Immobilization of anionic metalloporphyrins on zinc hydroxide nitrate and study of an unusual catalytic ac-tivity, J. Catal. 274 (2010) 130-141.

[8] K.A.D.F. Castro, S. Silva, P.M.R. Pereira, M.M.Q. Simões, M.G.P.M.S. Neves, J.A.S Cavaleiro, F. Wypych, J.P.C. Tomé, S. Nakagaki, Galactodendritic por-phyrinic conjugates as new biomimetic catalysts for oxidation reactions, Inorg. Chem. 54 (2015) 4382-4393.

[9] K.S. Suslick, P. Bhyrappa, J.-H. Chou, M.E. Kosal, S. Nakagaki, D.W. Smithenry, S.R. Wilson, Microporous porphyrin solids, Acc. Chem. Res. 38 (2005) 283-291.

[10] M. Xie, X. Yang, Y. He, J. Zhang, B. Chen, C. Wu, Highly efficient C-H oxidative activation by a porous MnIII-porphyrin metal-organic framework under mild conditions, Chem. Eur. J. 19 (2013) 14316-14321.

[11] A.M. Shultz, O.K. Farha, J.T. Hupp, S.T. Nguyen, Synthesis of catalytically active porous organic polymers from metalloporphyrin building blocks, Chem. Sci.2 (2011) 686-689.

[12] H.J. Mackintosh, P.M. Budd, N.B. Mckeown, Catalysis by microporous phthalocyanine and porphyrin network polymers, J. Mater. Chem. 18 (2008) 573-578.

[13] A.R. Oveisi, K. Zhang, A. Khorramabadi-zad, O.K. Farha, J.T. Hupp, Stable and catalytically active iron porphyrin-based porous organic polymer: Activity as both a redox and Lewis acid catalys, Sci. Rep. 5 (2015) (8 pp.).

[14] P. Kaur, J.T. Hupp, S.T. Nguyen, Porous organic polymers in catalysis: opportunities and challenges, ACS Catal. 1 (2011) 819-835.

[15] N.B. McKeown, Polymers of intrinsic microporosity, ISRN Mater. Sci. (2012) (16 pp.).

[16] N.B. McKeown, S. Hanif, K. Msayib, C.E. Tattershall, P.M. Budd, Porphyrin-based nanoporous network polymers, Chem. Commun. (2002) 2782-2783.

[17] A.M. Rocha-Gonsalves, J.M.T.B. Varejão, M.M. Pereira, Some new aspects related to the synthesis of meso-substituted porphyrins, J. Heterocycl. Chem. 28 (1991) 635-640.

[18] A.D. Adler, F.R. Longo, F. Kampas, J. Kim, On the preparation of metalloporphyrins, J. Inorg. Nucl. Chem. 32 (1970) 2443-2445.

[19] B.S. Ghanem, M. Hashem, K.D.M. Harris, K.J. Msayib, M. Xu, P.M. Budd, N. Chaukura, D. Book, S. Tedds, A. Walton, N.B. McKeown, Triptycene-based polymers of intrinsic microporosity: organic materials that can be tailored for gas adsorption, Macromolecules 43 (2010) 5287-5294.

[20] R.G.D. Taylor, C.G. Bezzu, M. Carta, K.J. Msayib, J. Walker, R. Short, B.M. Kariuki,
N.B. McKeown, The synthesis of organic molecules of intrinsic microporosity de-signed to frustrate efficient molecular packing, Chem. Eur. J. 22 (2016) 2466-2472.

[21] H. Saltzman, J.G. Sharefkin, Iodosobenzene. Org. Synth. 4343 (1963) 60-61.

[22] K.S.W. Sing, D.H. Everett, R.A.W. Haul, L. Moscou, R.A. PIerotti, J. Rouquerol, T. Siemieniewska, Reporting physisorption data for gas/solid systems with special reference to the determination of surface area and porosity, Pure Appl. Chem. 57 (1985) $603-619$

[23] M. Hashem, C.G. Bezzu, B.M. Kariuki, N.B. McKeown, Enhancing the rigidity of a network polymer of intrinsic microporosity by the combined use of phthalocyanine and triptycene components, Polym. Chem. 2 (2011) 2190-2192.

[24] L.J. Boucher, Manganese porphyrin complexes. III. Spectroscopy of chloroaquo complexes of several porphyrins, J. Am. Chem. Soc. 92 (1970) 2725-2730.

[25] P. Battioni, O. Brigaud, H. Desvaux, D. Mansuy, T.G. Traylor, Preparation of functionalized polyhalogenated tetraarylporphyrins by selective substitution of the $\mathrm{p}$ fluorines of mesotetra-(pentafluorophenyl)porphyrins, Tetrahedron Lett. 32 (1991) 28932896

[26] J.I.T. Costa, A.C. Tomé, M.G.P.M.S. Neves, J.A.S. Cavaleiro, 5,10,15,20-tetrakis (pentafluorophenyl)porphyrin: a versatile platform to novel porphyrinic materials, J. Porphyr. Phthalocyanines 15 (2011) 1116-1133.

[27] K.A.D.F. Castro, M.M.Q. Simões, M.G.P.M.S. Neves, J.A.S. Cavaleiro, F. Wypych, S. Nakagaki, Glycol metalloporphyrin derivatives in solution or immobilized on LDH and silica: synthesis, characterization and catalytic features in oxidation re-actions, Catal. Sci. Technol. 4 (2014) 129-141.

[28] K.A.D.F. Castro, M.M.Q. Simões, M.G.P.M.S. Neves, J.A.S. Cavaleiro, R.R. Ribeiro, F. Wypych, S. Nakagaki, Synthesis of new metalloporphyrin derivatives from [5,10,15,20-tetrakis (pentafluorophenyl)porphyrin] and 4-mercaptobenzoic acid for homogeneous and heterogeneous catalysis, Appl. Catal. A Gen. 503 (2015) 9-19.

[29] G.K.B. Ferreira, K.A.D.F. Castro, G.S. Machado, R.R. Ribeiro, K.J. Ciuffi, G.P. Ricci, J.A. Marques, S. Nakagaki, Manganese porphyrin in solution and heterogenized in diff erent materials mediates oxidation of hydrocarbons by iodosylbenzene, J. Mol. Catal. A Chem. 378 (2013) 263-272.

[30] F.B. Zanardi, I.A. Barbosa, P.C.S. Filho, L.D. Zanatta, D.L. da Silva, O.A. Serra, Y. Iamamoto, Manganese porphyrin functionalized on $\mathrm{Fe}_{3} \mathrm{O}_{4} @ \mathrm{nSiO}_{2} @ \mathrm{MCM}-4$ magnetic composite: structural characterization and catalytic activity as cyto-chrome P450 model, Microporous Mesoporous Mater. 219 (2016) 161-171.

[31] C. Zou, T. Zhang, M. Xie, L. Yan, G. Kong, X. Yang, A. Ma, C. Wu, Four metalloporphyrinic frameworks as heterogeneous catalysts for selective oxidation and aldo reaction, Inorg. Chem. 52 (2013) 3620-3626.

[32] L.D. Zanatta, I.A. Barbosa, F.B. Zanardi, P.C. SousaFilho, L.B. Bolzon, A.P. Ramos, O.A. Serra, Y. Iamamoto, Hydrocarbon oxidation by iron-porphyrin immobilized on SBA-15 as biomimetic catalyst: role of silica surface, RSC Adv. 6 (2016) 104886-104896.

[33] W. Zhang, P. Jiang, Y. Wang, J. Zhang, J. Zheng, P. Zhang, Selective oxidation over a metalloporphyrinic metal-organic framework catalyst and insights into the me-chanism of bicarbonate ion as co-catalyst, Chem. Eng. J. 257 (2014) 28-35.

[34] W. Zhang, P. Jiang, Y. Wang, J. Zhang, P. Zhang, Directing two azo-bridged covalent metalloporphyrinic polymers as highly efficient catalysts for selective oxidation, Appl. Catal. A Gen. 489 (2015) 117-122.

[35] W. Zhang, P. Jiang, Y. Wang, J. Zhang, P. Zhang, An efficient catalyst based on a metal metalloporphyrinic framework for highly selective oxidation, Catal. Lett. 145 (2015) $589-595$ 